\title{
Fistula Cannulation with a Novel Fistula Cannula: A Review of Cannulation Devices and Procedures
}

\author{
Federico Nalesso $^{a, b}$ Francesco Garzotto $^{a, b}$ Eva Muraro ${ }^{b}$ \\ Alessandra Brendolan ${ }^{a, b}$ Claudio Ronco ${ }^{a, b}$

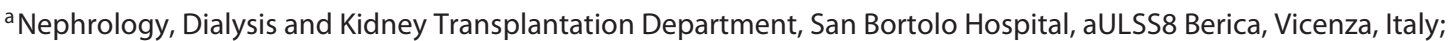 \\ bIRRIV, International Renal Research Institute Vicenza, Vicenza, Italy
}

\section{Keywords}

Fistula $\cdot$ Cannulation · Vascular access · Dialysis · Needle $\cdot$

Puncture $\cdot$ Safety

\begin{abstract}
Arteriovenous fistula cannulation for dialysis treatments in Europe has traditionally been done by metal needles. In Japan, plastic cannulas have been available for many years and are used in the majority of the dialysis patients. The mechanical structure and the cannulation procedure of the plastic cannulas differ from those of the metal needles. These differences are particularly beneficial for patients with delicate fistulas, tortuous vessels, metal allergies, oligophrenic patients, and also for the safety of the medical staff. In this paper, we present the main features of a novel fistula plastic cannula and the innovations introduced by it compared to the traditional metal needles.

(c) 2018 S. Karger AG, Basel
\end{abstract}

\section{Introduction}

Performing an adequate haemodialysis treatment requires a well-functioning vascular access that is long-lasting and has the least number of possible complications [1]. An arteriovenous fistula created with native vessels (AVF) is the vascular access of choice for a haemodialysis patient insofar, under equal flow, it exhibits a lower rate of complications and longer survival compared to protheses and central venous catheters $[2,3]$.

From an operating point of view, the venous puncture of the AVF entails a microtrauma that can cause hyperplasia of the intima and consequent vessel stenosis [4]. Over time, repeated punctures in the same area also entail weakness of the vessel wall, which causes aneurysms to form [5]. In 35\% of venous punctures, the positioning of the needle through the vessel wall causes a certain degree of anatomical damage due to direct injury or to decubitus

\section{KARGER}

(c) 2018 S. Karger AG, Basel

E-Mail karger@karger.com

www.karger.com/bpu
Prof. Claudio Ronco

Department of Nephrology, Dialysis and Transplantation

International Renal Research Institute of Vicenza (IRRIV), St. Bortolo Hospital

Viale Rodolfi, 37, IT-36100 Vicenza (Italy)

E-Mail cronco@goldnet.it 
of the needle on the wall. This can also facilitate local clotting leading to an increased risk of thrombosis of the fistula and loss of the access [5].

Therefore, the operator should make the choice of the needle based on the characteristics of the vascular access, the desired blood flow and the acute and chronic complications present at the time of the procedure. Of fundamental importance is the puncture technique used, which proves to be site-specific, as well as the level of expertise of the site itself in the management of the cannulation of complicated and uncomplicated vascular access.

The data existing in scientific literature do not provide exact indications on the type of device that should be used for fistula or prosthesis punctures and therefore that choice still lies with elements based on local needs, nurse experience, device availability, and the policy of preventing complications associated with the cannulation procedure itself, especially in new and complicated accesses. No less interesting is the issue of cannulation in vascular accesses that function well in terms of flow but are anatomically difficult to puncture due to their location, their depth compared to the cutaneous plane and their nonlinear shape.

The aim of this review is to examine the state of the art of the devices used for the cannulation of arteriovenous fistulas in dialysis to present the main features of a novel fistula plastic cannula recently launched in the market and to describe the advantages that this new technology offers to patients and nurses.

\section{The Japanese and Australian Experience}

In Europe, metal needles are used almost exclusively, whereas in Japan, plastic cannulas have been available for many years and are used in most vascular accesses $[6,7]$. According to official data, there are approximately 300,000 patients in Japan who undergo extracorporeal blood purification every week; many of these use cannulas rather than metal needles with excellent results as evinced by reduced complications [8]. From an operating point of view, professional incidents due to accidental puncture, specifically in hepatitis $\mathrm{C}$ virus (HCV), hepatitis $\mathrm{B}$ virus (HBV) and human immunodeficiency virus (HIV) patients, are avoided.

The use of cannulas for haemodialysis was recently also introduced in Australia [9], based on Japanese experience, insofar as excellent results have been observed in vascular accesses using plastic cannulas. To be highlighted are some differences in dialysis methods in Japan and in Australia, which can also be found in European practices.

Fistula Cannulation with a Novel Fistula Cannula
Table 1. Available sizes of metal needles for haemodialysis

\begin{tabular}{llll}
\hline Gauge & $\begin{array}{l}\text { External } \\
\text { diameter, } \mathrm{mm}\end{array}$ & $\begin{array}{l}\text { Internal } \\
\text { diameter, } \mathrm{mm}\end{array}$ & Length, mm \\
\hline $14 \mathrm{G}$ & 2.11 & 1.6 & 20,25 \\
$15 \mathrm{G}$ & 1.83 & 1.372 & $15,20,25,32$ \\
$16 \mathrm{G}$ & 1.65 & 1.194 & $15,20,25$ \\
$17 \mathrm{G}$ & 1.47 & 1.067 & $15,20,25$ \\
$18 \mathrm{G}$ & 1.27 & 0.838 & 20 \\
\hline
\end{tabular}

First of all, blood flow $(\mathrm{Qb})$ in Japan does not exceed $200 \mathrm{~mL} / \mathrm{min}$ (compared to a maximum of $300 \mathrm{~mL} / \mathrm{min}$ in Australia). As far as European practice is concerned, blood flows reach up to $350-380 \mathrm{~mL} / \mathrm{min}$, especially in haemofiltration and haemodiafiltration treatments. In Japan, likely due to anatomical and access management reasons, there is less use of vascular prostheses in favour of arteriovenous fistulas which are made in smaller sizes. For both these reasons, smaller sized needles are used (16 and $17 \mathrm{G}$ ) compared to the common practice in Australia and Europe.

\section{Characteristics of Traditional Needles and Fistula Cannulas}

The effective blood flow (QB) developed during the course of haemodialytic treatment is influenced by the size of the needles or cannulas and by the haemodynamic conditions of the arteriovenous fistula. Needles and cannulas are available in different diameters and lengths. The larger the internal diameter is and the shorter the needle or cannula, the greater the blood flow that can be reached, under equal inflow pressure conditions. In fact, the resistance determined by such blood flow devices depends linearly on their length and inversely on the fourth power of the internal radius of the device. In Europe, metal needles for arterial and venous access are available in the sizes stated in Table 1.

Specifically, the mechanical structure of a fistula cannula is more complex than that of a metal needle. In fact, every fistula cannula consists of a flexible plastic cannula and a stainless steel internal metal needle that serves as introducer for positioning the cannula inside the vessel. The introducer has a smaller diameter than the cannula, in particular, the diameter of the introducer needle is smaller than the internal diameter of the cannula where it resides in the positioning procedures; it follows that parietal damage due to vessel cannulation is lower. The size difference between the cannula and the introducer needle has been estimated to be $2 \mathrm{G}$ [10]. The endothelial dam- 
Table 2. Sizes available of Medtronic Argyle ${ }^{\circledR}$ fistula plastic cannula

\begin{tabular}{llll}
\hline Gauge & $\begin{array}{l}\text { External } \\
\text { diameter, } \mathrm{mm}\end{array}$ & $\begin{array}{l}\text { Internal } \\
\text { diameter, } \mathrm{mm}\end{array}$ & $\begin{array}{l}\text { Cannula length, } \\
\mathrm{mm}\end{array}$ \\
\hline $15 \mathrm{G}$ & 1.9 & 1.372 & 30,38 \\
$16 \mathrm{G}$ & 1.7 & 1.194 & 30,38 \\
$17 \mathrm{G}$ & 1.5 & 1.067 & 30,38 \\
\hline
\end{tabular}

age caused by the small introducer is therefore lower compared with consequent injury from use of the traditional needle. This phenomenon has already been described by some authors who have detected a lower incidence of vessel damage during the course of a puncture with a cannula [11].

Usually, metal needles have a back-eye that ensures optimum blood flow and minimises the risk of adhesion of the needle to the vessel wall $[12,13]$. Plastic cannulas instead have small holes all along the circumference of their end portion in order to improve blood flow and prevent occlusion of the cannula by the vessel wall [14].

In Table 2 are shown the available sizes for the fistula cannula that is utilized and studied in our dialysis center (Argyle ${ }^{\circledR}$, Medtronic), the only device of its category with both anti-reflux valve and safety mechanism against needle stick injuries. It is to be recalled that the Gauge stated corresponds to the diameter of the cannula and not of the introducer, which is normally 2 Gauge lower. The length also refers to the cannula, whereas the introducer is longer.

An important element for a cannulation procedure, blood sampling or nurse safety is the presence of a builtin Luer-Lock activated anti-reflux valve that allows for preventing blood reflux during the manoeuvre of connecting and disconnecting the device for extracorporeal circulation lines or from blood sampling devices. Safety in the use of the device is implemented also with the presence of a safety cap that seals the introducer needle tip and does not allow access to the sharp end portion once the introducer itself is removed from the cannula at the end of the cannulation manoeuvre. This way, it is not possible for nurses to accidentally stick themselves with the sharp end of the device, which can then be disposed of completely safely in sharp containers.

\section{Arteriovenous Fistula Cannulation Procedure}

The procedure of introducing a cannula into the arteriovenous fistula is considerably different from the procedure of introducing a metal needle.
The cannula is introduced into the vessel using an introducer needle (mandrel) that allows for puncturing the skin and the vessel wall. Once the mandrel is introduced into the vessel lumen and the flashback of blood has arrived at the introducer's end chamber, the cannula can be advanced inside the lumen using the path created by the mandrel. In addition, since the cannula is flexible and lacks a sharp tip, it can be pushed inside the vessel without causing injuries to the walls and can therefore follow the vessel's non-rectilinear trajectory. During the cannulation process, the mandrel is retracted as soon as the vessel lumen is reached, and the cannula continues safely inside it $[7,15,8]$.

Contrary to what happens with traditional needle puncture, the blood flowing back into the cannula is not pulsating in that the introducer's end chamber can only indicate the presence of the sharp end inside the vessel but does not act as a pulsating expansion vessel as occurs in the portion of the tube (at least $15 \mathrm{~cm}$ ) connected to the traditional needle. The nurse is capable of noting the presence of the cannula needle inside the vessel thanks to the flashback of blood at the mandrel's end chamber; this can entail a reduction of the feedback on the correct positioning of the device inside the fistula [15] if the cannulation procedure is not performed correctly and done by competent and trained personnel.

In addition, the cannula does not have wings for fixation to the skin [15]; this may entail difficulties for the nurse who must be careful not to extract the cannula after the puncture of the fistula and must come up with alternative skin fixation systems compared to the procedures provided for standard needles. Lastly, the introducer is much longer than a standard haemodialysis needle for which it should not be inserted completely into the vessel, but the insertion manoeuvre must be interrupted as soon as the flashback of blood arrives at the end chamber, therefore proceeding with the introduction of the cannula alone into the vessel lumen. All these aspects imply a special manual skill for nurses who must modify the cannulation technique compared to what is done with standard needles; consequently, training for handling the procedure is greater and more complex.

Thanks to an anti-reflux valve system, blood does not flow back outside the cannula during insertion into the vessel $[6,15]$; this mechanism allows for greater safety both for the nurse and for the patient, and prevents blood loss outside of the vessel in the event of accidental disconnection of the blood lines from the plastic cannula. 


\section{Discussion}

In managing a patient with Stage V CKD under extracorporeal purification treatment, the functionalities and the preservation of vascular access play a fundamental role in that they ensure the administration of effective and continuing purification treatment over time.

Each acute vascular access complication, associated with the cannulation procedure or needle repositioning, exposes the patient to damage that may entail an acute dysfunction of the access itself with the need, in some cases, for positioning a temporary central venous catheter in the event of significant blood extravasation or the development of aneurysmal areas with overlapping skin injuries.

Given haemodialysis patients' increasingly advanced age and the presence of comorbidities such as diabetes mellitus, very often it is necessary to create and re-create arteriovenous fistulas with vessels that are not entirely suitable in terms of trajectory, cannulation and creation site. In specific cases, the cannulation procedure is made difficult by multiple factors.

The patient's poor cooperation may be such that the patient's own movements may cause injuries of the vessel wall due to the sharp portion of the needle that impacts the vessel wall. Another problem concerns oligophrenic patients that do not maintain the position of the limb where the AVF is located. In very rare cases, there is a metal allergy-intolerance that makes use of the standard needle absolutely contraindicated.

Infiltration of the vessel wall of the arteriovenous fistula or of the prosthesis can occur as a result of repositioning of the tip of the metal needle during the haemodialysis session, which goes through the vessel wall causing bleeding of the surrounding tissues. This event usually appears either during puncturing of the AVF or as a result of patient movements during treatment.

Substituting metal needles with fistula cannulas can reduce the risk of infiltration, insofar as the cannulas, once inserted, do not manage to penetrate the vessel wall [7], thanks to greater adaptability provided by the flexible material and the lack of a sharp portion.

The characteristic of flexibility of the fistula cannula, contrary to the rigidity of the traditional needle, allows for being able to proceed with cannulation of the vascular access even in difficult puncture regions or in which the vessel begins to curve and is therefore not coplanar to the needle used. This characteristic allows cannulas to be used also in regions in which the portion to cannulate is reduced in its extension and not perfectly adjacent on the same plane $[7,15]$. Many patients in Japan are punctured

Fistula Cannulation with a Novel Fistula Cannula near or at the level of the crease of the elbow, a region in which the vessel often is tortuous and highly subject to injuries from movements by the sharp portion of the needle. The possibility of puncturing the fistula in these areas as well increases the cannulation area and allows for rotating the puncture sites so as to minimise the formation of aneurysms and increase the age of survival of the access, reducing chronic and acute complications [7].

Generally, during a haemodialysis session, much care must be given to immobilise the patient's arm so as not to sustain injuries of the vessel by the sharp needle, which remains inserted during treatment [5]. The use of cannulas out of plastic material prevents this risk, becoming the most suitable solution, especially in less cooperative patients (elderly with cognitive impairment, patients with mental retardation).

The cannula's particular geometry, once the mandrel is extracted, allows it to be moved completely safely during fixation and/or repositioning procedures, since no sharp portion is present inside the vessel that can cause wall injuries by direct mechanical impact. Since the standard needle is rigid and is equipped with a sharp end, it is capable of causing wall injuries during such manoeuvres even if performed with extreme care by expert staff. The rigidity of this device does not allow it to follow the vessel lumen bending according to the trajectory of the said vessel.

Another element of great importance is the possibility of proceeding with direct pressure on the cannula insertion point at the time of its extraction from the vessel lumen at the end of the dialysis treatment. During this procedure, the cannula, in fact, cannot cause any injury to the vessel wall and surrounding tissues in that it is not equipped with sharp portions. To the contrary, the traditional needle, if applied with excessive or premature pressure, can cause injury to the wall and the surrounding soft tissues. Great wall breach sizes are reflected in an increased vascular access haemorrhage time [7].

As far as nurse safety is concerned, the presence of an ad hoc device to seal the tip of the mandrel of the fistula cannula, once extracted, prevents any possible accidental puncture of the nurse. This fact is of particular importance in the event of use in patients positive for $\mathrm{HIV} / \mathrm{HBV} / \mathrm{HCV}$. The possibility of having a mandrel with a sealed sharp tip also increases workplace safety insofar as no device is present that can cause accidental puncture in other agents interacting with the nurse in charge of the vascular access puncture and the removal of the fistula cannula at the end of the extracorporeal treatment. 
Table 3. Innovations introduced with the use of the fistula cannula compared to the traditional needle

\begin{tabular}{llll}
\hline & Traditional needle & Fistula cannula & Fistula cannula innovation \\
\hline $\begin{array}{l}\text { Accidental puncture of the rear wall } \\
\text { of the vessel during cannulation of } \\
\text { vascular access }\end{array}$ & Frequent & Reduced & $\begin{array}{l}\text { Absence of sharp tip at the end of the } \\
\text { cannula inserted in the vessel lumen }\end{array}$ \\
\hline
\end{tabular}

Lateral - medial wall injury during $\quad$ Frequent
cannulation

Once the mandrel is removed, the cannula does not cause wall injuries even if it comes repeatedly into contact with it due to lack of a sharp tip

\begin{tabular}{|c|c|c|c|}
\hline $\begin{array}{l}\text { Puncture of sites that are deep and } \\
\text { difficult to reach }\end{array}$ & Difficult procedure & Easy procedure & $\begin{array}{l}\text { Once it has entered the vessel, the } \\
\text { mandrel is retracted, and the cannula } \\
\text { can proceed inside the vessel following } \\
\text { its curvature }\end{array}$ \\
\hline
\end{tabular}

\begin{tabular}{|c|c|c|c|}
\hline Puncture of the crease of the elbow & Difficult procedure & Easy and safe procedure & $\begin{array}{l}\text { During movements, the cannula does not } \\
\text { cause wall injuries due to lack of a sharp tip }\end{array}$ \\
\hline $\begin{array}{l}\text { Puncture of non-rectilinear AVF } \\
\text { sections }\end{array}$ & Difficult procedure & Easy and safe procedure & $\begin{array}{l}\text { Adaptability of the cannula that is flexible } \\
\text { to vessel angles on three planes }\end{array}$ \\
\hline
\end{tabular}

\begin{tabular}{|c|c|c|c|}
\hline Use in patients allergic to metals & Not usable & Usable & Non-metallic, flexible plastic material \\
\hline
\end{tabular}

\begin{tabular}{|c|c|c|c|}
\hline $\begin{array}{l}\text { Injuries of the walls of the vascular } \\
\text { access during needle repositioning } \\
\text { phases due to malfunctioning of the } \\
\text { extracorporeal circulation system }\end{array}$ & Frequent & Not possible & $\begin{array}{l}\text { Repositioning of the cannula does not cause } \\
\text { wall damage due to the cannula's flexibility } \\
\text { and lack of a sharp tip. The cannula adapts } \\
\text { to the vessel's geometry being flexible }\end{array}$ \\
\hline
\end{tabular}

Use in poorly cooperative patients Difficult to use $\quad$ Easy and safe procedure $\quad$ Repositioning of the cannula does not cause
for maintaining the position of the AVF limb Repositioning of the cannula does not cause
wall damage due to the cannula's flexibility and lack of a sharp tip. The cannula adapts to the vessel's geometry, given its flexibility. Upon movement of the limb, the cannula adapts to the new position of the vascular access

\begin{tabular}{llll}
\hline Fixation to patient's skin & Easy & Not immediate & $\begin{array}{l}\text { Lack of plastic wings or similar devices that } \\
\text { allow its fixation with tape/other fixation } \\
\text { devices }\end{array}$ \\
\hline $\begin{array}{l}\text { External bloody effusion during } \\
\text { extracorporeal line connection and } \\
\text { disconnection procedures }\end{array}$ & Possible & Impossible & $\begin{array}{l}\text { Presence of anti-reflux valve with } \\
\text { Luer-Lock connection }\end{array}$ \\
$\begin{array}{l}\text { External bloody effusion during the } \\
\text { blood draw procedure pre- and/or } \\
\text { post-extracorporeal circulation }\end{array}$ & Possible & Impossible & $\begin{array}{l}\text { Presence of anti-reflux valve with } \\
\text { Luer-Lock connection }\end{array}$ \\
$\begin{array}{l}\text { Accidental puncture of the nurse } \\
\text { Possible }\end{array}$ & Pressible & Imposence of sealing cap device that seals the \\
& & $\begin{array}{l}\text { Presen portion of the mandrel not making it } \\
\text { sharp } \\
\text { accessible }\end{array}$
\end{tabular}

\footnotetext{
${ }^{\circ}$ Vascular access difficult to puncture due to vessel depth greater than $6 \mathrm{~mm}$ from the cutaneous plane, presence of non-rectilinear vessels with or without aneurysmal dilations or stenotic sections.

* Post-cannulation haematoma, blood extravasation in the soft tissues after needle removal, presence of significant aneurysmal dilations, non-rectilinear vessel due to dislocation of hematomas or blood extravasations, presence of pseudoaneurysms from puncture.
} 
The presence of the anti-reflux valve eliminates the possibility of blood loss occurring in the event of disconnection of other devices of the fistula cannula, which is also important for the safety of nurses who should not operate in the presence of blood in the environment.

\section{Conclusions}

Fistula cannulas definitely offer improved features that make their use safer and easier even in a standard population of haemodialysis patients. Different techniques can therefore be applied effectively (26-30). Cer- tainly, the technological innovation of these devices is more evident in cases of difficult access puncture or use in the presence of acute/chronic vascular access complications. Nurse safety is notably improved by the reduction of possible environmental contamination and needle stick injury risk.

The possibility of having a Luer-Lock connection equipped with an anti-reflux valve also means a simplification of the phases of connection and disconnection of the device from the extracorporeal circulation or from the different devices to perform a blood sample for biochemical analysis. Table 3 summarises the innovations introduced with the use of the fistula cannula compared to the traditional needle.

\section{References}

1 McCann M, Einarsdóttir H, Van Waeleghem JP, Murphy F, Sedgewick J: Vascular access management 1: an overview. J Ren Care 2008; 34:77-84.

2 III. K/DOQI clinical practice guidelines for vascular access: update 2000. Am J Kidney Dis 2001;37(1 suppl 1):S137-S181.

3 Gibson KD, Gillen DL, Caps MT, et al: Vascular access survival and incidence of revisions: a comparison of prosthetic grafts, simple autogenous fistulas, and venous transposition fistulas from the United States Renal Data System Dialysis Morbidity and Mortality Study. J Vasc Surg 2001;34:694700.

4 Hsiao JF, Chou HH, Hsu LA, et al: Vascular changes at the puncture segments of arteriovenous fistula for hemodialysis access. J Vasc Surg. 2010;52:669-673.
5 Lee T, Barker J, Allon M: Needle infiltration of arteriovenous fistulae in hemodialysis: risk factors and consequences. Am J Kidney Dis 2006;47:1020-1026.

6 Grainer F: Plastic (non-metal) fistula cannula: from concept to practice. Ren Soc Australas J 2014; 10:44-46.

7 Du Toit D: Haemodialysis needles: why do we use metal fistula needles? Ren Soc Australas J 2013;9:138-140.

8 Parisotto MT, Pelliccia F, Bedenbender-Stoll E, Gallieni M: Haemodialysis plastic cannulae - a possible alternative to traditional metal needles? J Vasc Access 2016;17:373-379.

9 Week R: Renal Society of Australia Annual Scientific Meeting, 2014.

10 Chapdelaine I, de Roij van Zuijdewijn CL, Mostovaya IM, et al; EUDIAL Group: Optimization of the convection volume in online post-dilution haemodiafiltration: practical and technical issues. Clin Kidney J 2015;8: 191-198.

11 Smith V, Schoch M: Plastic cannula use in hemodialysis access. J Vasc Access 2016;17:405410.

12 Brouwer DJ: Cannulation camp: basic needle cannulation training for dialysis staff. Dial Transplant 2011;40:434-439.

13 Van Loon M: How to improve vascular access care; in Widmer NK, Malik J (eds): Patient Safety in Dialysis Access. Contrib Nephrol. Basel, Karger, 2015, vol 184, pp 222-233.

14 National Kidney Foundation: Needles and Cannulas For Arteriovenous Fistula Access, 2016.

15 Smith V, Schoch M; Plastic cannula use in hemodialysis access. J Vasc Access 2016;17:405410 